\title{
Feasibility and patient satisfaction with smoking cessation interventions for prevention of healthcare-associated infections in inpatients
}

Danielle M. Schulte ${ }^{1,2}$, Megan Duster $^{1}$, Simone Warrack ${ }^{1}$, Susan Valentine', Douglas Jorenby ${ }^{1,3}$, Daniel Shirley ${ }^{1}$, James Sosman ${ }^{1}$, Sheryl Catz ${ }^{4}$ and Nasia Safdar ${ }^{1,5,6^{*}}$

\begin{abstract}
Background: Smoking increases hospitalization and healthcare-associated infection. Our primary aim of this pilot, randomized-controlled trial was to examine the feasibility and acceptability of a tobacco cessation intervention compared with usual care in inpatients. S. aureus carriage, healthcare-associated infections and infections post discharge were exploratory outcomes.

Methods: Current inpatient smokers from a university hospital facility were randomized to usual care or a face to face tobacco cessation counseling session where patients' tobacco use and strategies for quitting were discussed. Patient engagement, satisfaction and withdrawal symptoms were measured at 1 week and 12 weeks post discharge. Nasal swabs were collected at enrollment and discharge and assessed for S. aureus colonization. P-values were calculated using Fisher's exact and t-tests were used to compare groups.

Results: For the study's primary outcome, participants reported the intervention as being generally acceptable and reported high overall levels of satisfaction, with a Likert scale score of at least $4 / 5$ for all measures of satisfaction. No subjects utilized free tobacco cessation services after discharge. $83 \%$ of the intervention group and $93 \%$ of the control group smoked at least one cigarette after discharge. Secondary outcomes with regard to infections showed that, at discharge, $12 \%$ of the intervention group $(n=17)$ and $18 \%$ of the control group $(n=22)$ tested positive for $S$. aureus. After 3 months, $9 \%$ of the intervention group developed infection, $41 \%$ visited an emergency room, and $24 \%$ were readmitted within 3 months post-discharge, compared to 27,32 and $36 \%$ of the control group respectively.

Conclusions: With regards to the primary aim of this study, there were overall high levels of satisfaction with the intervention, indicating good feasibility and acceptance among patients. However, more intensive interventions in hospitalized patients and impact on healthcare-associated infections and post-discharge infections should be explored.
\end{abstract}

Keywords: Healthcare-associated infections, Staphylococcus aureus, MRSA, Tobacco cessation, Infection control

\footnotetext{
* Correspondence: ns2@medicine.wisc.edu

${ }^{1}$ Department of Medicine, University of Wisconsin-Madison School of

Medicine and Public Health, Madison, WI, USA

${ }^{5}$ University of Wisconsin Hospitals and Clinics, Madison, WI, USA

Full list of author information is available at the end of the article
}

\section{Biomed Central}

C 2016 Schulte et al. Open Access This article is distributed under the terms of the Creative Commons Attribution 4.0 International License (http://creativecommons.org/licenses/by/4.0/), which permits unrestricted use, distribution, and reproduction in any medium, provided you give appropriate credit to the original author(s) and the source, provide a link to the Creative Commons license, and indicate if changes were made. The Creative Commons Public Domain Dedication waiver (http://creativecommons.org/publicdomain/zero/1.0/) applies to the data made available in this article, unless otherwise stated. 


\section{Background}

Smoking is a major risk factor for many types of infections [1]. Adult smokers are at increased risk of respiratory colonization and infection by several bacterial pathogens, including Streptococcus pneumonia, Neisseria meningitidis, Haemophilus influenzae and Legionella pneumophila [2-6]. The nasal flora of smokers has also been shown to contain fewer normal bacteria and more pathogenic organisms, but this imbalance can revert to normal after quitting smoking [2-6]. Direct evidence linking smoking to an increased risk of healthcareassociated infection (HAI) is limited. However, because tobacco use affects an individual's normal flora [6] and negatively affects the immune system $[7,8]$, the connection has been established with one study that showed a $75 \%$ increased risk of Clostridium difficile-associated diarrhea in smokers compared with non-smokers [9]. HAIs such as $C$. difficile colitis, methicillin-resistant Staphylococcus aureus (MRSA) and respiratory infections are of major public health importance; prevention of HAIs has been deemed essential by all major public health agencies [10-12]. Given that smoking increases the risk of HAI, strategies for tobacco cessation may be important in reducing the burden of HAI.

Limited data exist on the utility of smoking cessation interventions for inpatients [13-15] and to our knowledge no study has examined the interaction between smoking cessation and HAI. Hospitals in the United States must have no-smoking policies for accreditation and therefore, a hospital stay requires a smoker to abstain temporarily from tobacco, offering hospitalized smokers an opportunity to initiate cessation. However, this can precipitate nicotine-withdrawal symptoms in hospitalized smokers, causing discomfort and potentially reducing smokers' adherence to no-smoking policies. Inpatient nicotine-replacement therapy reduces the symptoms of nicotine withdrawal and could increase the chance of remaining abstinent from tobacco after discharge. In fact, the Agency for Healthcare Research and Quality recommends that all hospitalized smokers be offered all effective smoking-cessation treatments and medications as outlined in the 2008 Clinical Practice Guideline [16]. However, there is great variability in the extent to which this is followed [17].

We undertook a pilot randomized-controlled trial at a tertiary care teaching hospital with the primary aim of examining the feasibility and acceptability of implementation of a brief intensive smoking cessation intervention for inpatient smokers compared with usual care. Accordingly, we examined patient satisfaction with the intervention methods as well as patient engagement and withdrawal symptoms, and, as an exploratory outcome, measured HAI and post discharge infections up to 3 months. We hypothesized that our proposed intervention to encourage tobacco cessation would be feasible and associated with high patient satisfaction.

\section{Methods}

A two-armed parallel design randomized trial was performed, comparing the feasibility of a tobacco cessation intervention with usual care smoking cessation in hospitalized patients. Potential participants from the University of Wisconsin Hospital \& Clinics inpatient units were identified by research team members using daily admission lists at the hospital. Current smokers (who smoked greater than 9 cigarettes per day on average for last 6 months prior to admission, and who also had an anticipated hospital stay of at least 3 days) aged 18 or older were identified from the electronic medical record. Patients admitted to the hospital within the last $24 \mathrm{~h}$ were approached for participation by the research team and were evaluated for their desire to quit smoking. Only patients with a motivation to quit were consented, enrolled, and randomized to receive either the study "intervention" or "usual care" for smoking cessation (Fig. 1). Randomization was achieved using a computer-generated randomization table created by the research team. The research team were aware of the subjects' randomization allocation at enrollment and follow-up so as to allow the appropriate intervention and follow-up questionnaire to be administered. Subjects were not made directly aware of their allocation, however due to differences in the cessation interventions, blinding was unable to be assured. Patients in the intensive care, neurology and psychiatric units were excluded from inclusion in the study as well as those prohibited by their nurses or doctors from participating. The study protocol was approved by the Institutional Review Board at the University of Wisconsin School of Medicine and Public Health.

\section{Usual care}

Usual care at our institution consisted of an assessment of tobacco use at admission, followed by a brief counseling session provided by the treating team during hospitalization, including evidence-based pharmacotherapy interventions such as nicotine patches, gum and lozenges, bupriopion and varencicline as applicable. The usual care counseling session was meant to educate patients on strategies for smoking cessation, and provide patients with informational and educational materials regarding smoking cessation.

\section{Intervention}

The study intervention consisted of a brief counseling session [18] provided by a research team member, trained in patient cessation methods and procedures, and introduction to the Wisconsin Quit Line. The Quit Line is a free and confidential smoking cessation resource that helps 




Fig. 1 Recruitment Consort Diagram

smokers create individualized tobacco cessation plans and offers free materials, medication and referrals to local tobacco cessation resources and services [19].

Lasting $15-20 \mathrm{~min}$, the trained researcher assessed subject readiness to quit, which consisted of open response self-report of the desire to quit, focused on individualized strategies for smoking cessation and provided patients with intervention-specific informational materials, including information on how to contact the Wisconsin Quit Line.

\section{Microbiology methods}

For all subjects, a nasal swab was collected upon study enrollment and upon hospital discharge to assess baseline $S$. aureus colonization. Specimens were enriched in broth and cultured on mannitol salt agar containing cefoxitin (4 micrograms $/ \mathrm{mL}$ ) for $48 \mathrm{~h}$. Catalase-positive, coagulase-positive, Gram positive cocci were confirmed as MRSA using the Kirby Bauer disc diffusion method. Swabs were not obtained at any subsequent ER or hospital visits as subjects were not followed in person after hospital discharge.

\section{Definition of Infections}

We used the Center for Disease Control and Prevention's definition of healthcare-associated infection defined as meeting criteria for infection for a specific body site on after the $3^{\text {rd }}$ calendar day of hospitalization [20].

\section{Follow-up procedures}

Post-discharge from the hospital, a follow-up phone call was made at two intervals, 2-7 days post-discharge and again at 12 weeks post-discharge by a trained research 
staff member. These calls were used to gauge subject engagement and identify any tobacco withdrawal symptoms. During each call, staff conducted a relapse assessment, obtained information on utilization of smoking cessation treatments (i.e., Wisconsin Tobacco Quit Line, nicotine patch, etc.) and conducted withdrawal assessment measures using validated measures of affect and nicotine withdrawal (Positive and Negative Affect Schedule [PANAS] and Wisconsin Smoking Withdrawal Scale [WSWS]) [21, 22]. Staff also utilized a self-efficiency assessment that consisted of a question regarding subjects' expectations on whether they would be a smoker in the future. In the intervention group, patient perceptions of the acceptability and satisfaction with the study intervention using a 5-point Likert scale and data on infection incidence and readmissions using a standardized questionnaire were also obtained. The answers for the 5point Likert scale spanned values from 1-5, with 1 representing "Not Satisfied at All" and 5 representing "Extremely Satisfied", and measured patient perceptions of the intervention content, length, and timing, the study team, physician support and family support. Relapse assessment and utilization of smoking cessation treatments were measured as occurring since the previous contact with research staff. HAI incidence and readmissions were measured as occurring any time since discharge. Subjects were also given an open-ended question, allowing for any additional comments concerning the study procedures to be made. Due to the nature of these assessments, researchers were not able to be blinded to participants' study group.

\section{Statistical analysis}

Mean group scores were calculated for each follow-up measure. Subjects' baseline characteristics and followup scores were compared using Fisher's exact tests and $t$-tests for categorical and continuous variables respectively in SAS 9.4 software (SAS Institute Inc., Cary NC USA). A $p$-value of $<0.05$ was considered statistically significant. Subjects with missing data were excluded from analysis.

\section{Results}

Thirty-nine subjects enrolled in the study. Twenty-two subjects were randomized to the usual care group and 17 were randomized to the intervention group (Fig. 1). Age was the only baseline feature of the groups to differ significantly, with those in the intervention group being older (Table 1). Seven individuals from the usual care group and two individuals from the intervention group did not have a discharge swab collected because they were discharged from the hospital before swabs could be obtained. After 1 week, 2 subjects were lost to follow-up leaving 16 subjects in the intervention arm and 21 subjects in the usual care arm. After 3 months, 10 more subjects were lost to follow-up leaving 12 subjects in the intervention arm and 15 subjects in the usual care arm.

At admission, $27 \%$ of subjects from the usual care group and $0 \%$ of subjects from the intervention group had nasal swabs positive for methicillin-susceptible Staphylococcus aureus (MSSA). At admission, $0 \%$ of subjects from the usual care group and $12 \%$ of subjects from the intervention group had nasal swabs positive for methicillin-resistant Staphylococcus aureus (MRSA). Among those who had a discharge swab collected, $27 \%$ of subjects from the usual care group and $7 \%$ of subjects from the intervention group had nasal swabs positive for MSSA and $0 \%$ from the usual care group $7 \%$ of subjects from the intervention group had a nasal swab positive for MRSA. One subject was observed to have been negative at admission and became MSSA positive at discharge (Table 1).

There were no statistically different relapse or health outcomes measured at 1 week or 3 months (Table 2). At each follow-up stage, subjects in both groups continued to have high smoking rates. At week one post discharge $68 \%$ of subjects smoked at least one cigarette since discharge. At the 3-month follow-up, $89 \%$ of subjects smoked at least one cigarette since discharge. One subject also reported developing an infection during a hospital stay, and 3 subjects at the one-week time point, and 5 subjects at 3-month follow-up, reported developing an infection post hospital discharge (Table 2). Infections included surgical site infection, urinary tract infection, sinus infection and pneumonia. Subjects also had high rates of emergency room visitation and hospital readmission post discharge. At one week, $10 \%$ of subjects had visited an emergency room, and at 3 months $36 \%$ of subjects had visited an emergency room. Also, at one week $8 \%$ of subjects had been readmitted to a hospital and at 3 months $31 \%$ had been readmitted. None of the subjects reported utilizing the Wisconsin Quit Line to aid in their smoking cessation attempt.

Subject satisfaction with the intervention was overall very high (Fig. 2). The average content satisfaction score was 4.13 (standard deviation $[\mathrm{SD}]=1.02$ ) on the Likert scale. The average length of intervention satisfaction score was $4.19(\mathrm{SD}=1.17)$. The average timing satisfaction score was $4.27(\mathrm{SD}=1.3)$. The average study team satisfaction score was $4.38(\mathrm{SD}=1.02)$. The average physician support satisfaction score was $4.31(\mathrm{SD}=0.87)$ and the average family support satisfaction score was $4.00(\mathrm{SD}=1.02)$. Additionally, one subject expressed a desire to have more counseling sessions be part of the intervention protocol and another suggested that the sessions be longer. Others also suggested that there be more immediate action from the intervention, so that, instead of having to wait until they were discharged, they 
Table 1 Baseline characteristics

\begin{tabular}{|c|c|c|c|}
\hline & $\begin{array}{l}\text { Intervention } \\
(n=17)\end{array}$ & $\begin{array}{l}\text { Usual care } \\
(n=22)\end{array}$ & $P$-value* \\
\hline $\begin{array}{l}\text { Mean age, years } \\
\text { (Standard deviation) }\end{array}$ & $53.5(12.5)$ & $44.7(12.8)$ & 0.039 \\
\hline Gender & & & 1.000 \\
\hline Males (\%) & $9(52.9 \%)$ & $12(54.5 \%)$ & \\
\hline Females (\%) & $8(47.1 \%)$ & 10 (45.5\%) & \\
\hline Race & & & 0.634 \\
\hline White/Caucasian (\%) & $12(70.6 \%)$ & $17(77.3 \%)$ & \\
\hline Black/African Am. (\%) & $2(11.8 \%)$ & 2 (9.1\%) & \\
\hline Other $^{a}$ & $1(5.9 \%)$ & $1(4.5 \%)$ & \\
\hline Not Reported (\%) & $2(11.8 \%)$ & 2 (9.1\%) & \\
\hline Ethnicity & & & 1.000 \\
\hline Hispanic (\%) & 0 & $1(4.5 \%)$ & \\
\hline Non-Hispanic (\%) & $15(88.2 \%)$ & 17 (77.3 \%) & \\
\hline Not Reported (\%) & $2(11.8 \%)$ & $4(18.2 \%)$ & \\
\hline \multicolumn{4}{|l|}{ Colonization } \\
\hline MSSA at baseline & 0 & $6(27.3 \%)$ & 0.063 \\
\hline MRSA at baseline & $2(11.8 \%)$ & 0 & 0.194 \\
\hline MSSA at discharge & $1(7.1 \%)$ & $4(26.7 \%)$ & 0.330 \\
\hline MRSA at discharge & 1 (6.7 \%) & 0 & 1.000 \\
\hline $\begin{array}{l}\text { Average cigarettes per } \\
\text { day (SD) }\end{array}$ & $17.6(9.0)$ & $16.5(11.5)$ & 0.944 \\
\hline \multicolumn{4}{|l|}{ Infection history } \\
\hline History of VRE (\%) & 0 & 0 & - \\
\hline History of MRSA (\%) & 0 & $1(4.5 \%)$ & 1.000 \\
\hline History of C. difficile (\%) & 0 & 0 & - \\
\hline \multicolumn{4}{|l|}{ Hosp history } \\
\hline $\begin{array}{l}\text { Hospitalized 3months. } \\
\text { prior (\%) }\end{array}$ & $2(11.8 \%)$ & $5(22.7 \%)$ & 0.438 \\
\hline $\begin{array}{l}\text { Surgery 3months. } \\
\text { prior (\%) }\end{array}$ & $2(11.8 \%)$ & $3(13.6 \%)$ & 1.000 \\
\hline \multicolumn{4}{|l|}{ Immuno comp. status } \\
\hline Active Cancer (\%) & $5(29.4 \%)$ & 1 (4.5\%) & 0.068 \\
\hline $\begin{array}{l}\text { Immunosuppressive Drugs } \\
30 \text { days prior (\%) }\end{array}$ & $2(11.8 \%)$ & 2 (9.1\%) & 1.000 \\
\hline Diabetes (\%) & $3(17.6 \%)$ & $6(27.3 \%)$ & 0.704 \\
\hline \multicolumn{4}{|l|}{ Comorbidities } \\
\hline Liver disease (\%) & 1 (5.9\%) & $4(18.2 \%)$ & 0.363 \\
\hline Cardiovascular disease (\%) & 10 (58.9\%) & 10 (45.5\%) & 0.523 \\
\hline Respiratory disease (\%) & $7(41.2 \%)$ & 10 (45.5\%) & 1.000 \\
\hline Gl disease (\%) & $6(35.3 \%)$ & $9(40.9 \%)$ & 0.753 \\
\hline \multicolumn{4}{|l|}{ Antibiotics } \\
\hline $\begin{array}{l}\text { Antibiotics within } \\
30 \text { days prior to admission (\%) }\end{array}$ & $3(17.6 \%)$ & $6(27.3 \%)$ & 0.704 \\
\hline \multicolumn{4}{|l|}{ Other risk factors } \\
\hline Open Wound (\%) & $4(23.5 \%)$ & $7(31.8 \%)$ & 0.725 \\
\hline Alcohol Use (\%) & $13(76.5 \%)$ & 13 (59.1 \%) & 0.456 \\
\hline
\end{tabular}

Table 1 Baseline characteristics (Continued)

\begin{tabular}{|c|c|c|c|}
\hline Drug Use (\%) & $3(17.6 \%)$ & $4(18.2 \%)$ & 1.000 \\
\hline AVG. length of stay (SD)* & $5.2(2.0)$ & $4.2(2.8)$ & 0.227 \\
\hline \multicolumn{4}{|c|}{$\begin{array}{l}\text { Continuous data were analyzed using } t \text {-tests and dichotomous data were } \\
\text { analyzed using Fisher's exact tests with significance delineated at } p<0.05 \\
\text { aOne subject in the intervention group reported his race to be African } \\
\text { American and Native American and one subject from the usual care group } \\
\text { reported his race to be "Mexican" } \\
\text { *One subject from the usual care group had a length of stay of } 26 \text { days and } \\
\text { was excluded from the average calculation }\end{array}$} \\
\hline
\end{tabular}

could actively engage in their tobacco cessation while still in the hospital (e.g., through the use of a nicotine patch or other medications). Lastly, some subjects suggested that the counseling session may be more effective if performed closer to their discharge from the hospital so that they were more likely to retain the information discussed during the encounter and not be as distracted by their current medical treatments.

At the week one follow-up, there were no statistically significant differences in the WSWS outcomes observed between the groups (Table 3). At the 3-month follow-up, the mean "thinking about food" score was significantly higher in the usual care group (Table 3). Additionally, the mean withdrawal assessment scores on the PANAS scale were not statistically significant at either follow-up time point (Table 4).

\section{Discussion}

In this study, aimed at examining the feasibility and acceptability of tobacco cessation interventions in hospitalized patients, we found that overall, while recruitment of subjects was achievable, retention in the study and collecting discharge swabs was a challenge in this group of patients. Subjects showed consistently low withdrawals symptom levels and only differed significantly in one WSWS scale measure and no PANAS scale measures. They also had high levels of satisfaction with the tobacco cessation intervention. For each measure of satisfaction, subjects reported an average Likert scale score of 4 or higher, out of a possible 5. Due to the high levels of satisfaction seen in our subjects upon administration of this intervention, we anticipate that interventions of this kind are acceptable to inpatients. However, close attention will need to be paid to put measures in place to minimize attrition and improve swab collection at discharge.

We also found that subject satisfaction with the intervention did not translate into cessation of tobacco use as we still observed low quit rates in each of the study groups. This low rate of tobacco cessation could also have influenced the low levels of withdrawal symptoms observed in the groups as well. There are a number of possible explanations for this finding. First, none of the subjects in either treatment or usual care group utilized free tobacco cessation services such as the Wisconsin 
Table 2 Relapse and health outcome week 1 and 3 months

\begin{tabular}{|c|c|c|c|c|}
\hline & Intervention $(n=17)$ & Usual care $(n=22)$ & Total $(n=39)$ & $P$-value \\
\hline \multicolumn{5}{|l|}{ Outcomes at week 1} \\
\hline Smoking since DC(\%) & $11 / 16(68.7 \%)$ & $14 / 21(66.6 \%)$ & $25 / 37(67.6 \%)$ & 1.000 \\
\hline Alcohol (\%) & $1 / 16(6.3 \%)$ & $2 / 21(9.5 \%)$ & $3 / 37$ & 1.000 \\
\hline Quit Line (\%) $)^{\mathrm{a}}$ & $0 / 8$ & $0 / 12$ & $0 / 20$ & - \\
\hline Other cessation program/Medication Use (\%) & $2 / 8(25.0 \%)$ & $0 / 12$ & $2 / 20(1.0 \%)$ & 0.164 \\
\hline Infection during stay (\%) & $0 / 16$ & $1 / 21(4.8 \%)$ & $1 / 37(2.7 \%)$ & 1.000 \\
\hline Infection Post DC (\%) & $1 / 16(6.3 \%)$ & $2 / 21(9.5 \%)$ & 3/37 (8.1 \%) & 1.00 \\
\hline ER visit $(\%)^{b}$ & 2/17 (11.8\%) & $2 / 22(9.1 \%)$ & 4/39 (10.3 \%) & 0.568 \\
\hline Hospital readmission $(\%)^{\mathrm{b}}$ & $1 / 17(5.9 \%)$ & $2 / 22(9.1 \%)$ & $3 / 39(7.7 \%)$ & 0.496 \\
\hline \multicolumn{5}{|l|}{ Outcomes at 3 months } \\
\hline Smoking in last 7 days (\%) & 8/12 (66.7 \%) & $11 / 15(73.3 \%)$ & 19/27 (70.4\%) & 1.000 \\
\hline Smoking at all since DC (\%) & 10/12 (83.3 \%) & 14/15 (93.3 \%) & $24 / 27(88.9 \%)$ & 0.569 \\
\hline Alcohol (\%) & $3 / 12(25.0 \%)$ & $4 / 15$ (26.7 \%) & $7 / 27(25.9 \%)$ & 1.00 \\
\hline Quit Line (\%) & $0 / 11$ & $0 / 14$ & $0 / 25$ & - \\
\hline Other cessation program/Medication Use (\%) & 2/11 (18.2\%) & $1 / 14(7.1 \%)$ & $3 / 25(12 \%)$ & 1.000 \\
\hline Infection Post DC (\%) & $1 / 11(9.1 \%)$ & 4/15 (26.7 \%) & $5 / 26(19.2 \%)$ & 0.614 \\
\hline ER visit $(\%)^{b}$ & $7 / 17(41.2 \%)$ & 7/22 (31.8\%) & 14/39 (35.9\%) & 0.689 \\
\hline Hospital readmission $(\%)^{\mathrm{b}}$ & $4 / 17(23.5 \%)$ & $8 / 22(36.4 \%)$ & $12 / 39(30.8 \%)$ & 1.000 \\
\hline
\end{tabular}

"Data analyzed using Fisher's exact analysis

${ }^{a}$ Quit Line and other program/medication use was included in the week 1 outcome follow-up beginning with patient 18 and in the 3 month outcome follow-up with subject 4

${ }^{\mathrm{b}}$ ER visitation and Hospital readmission data were compiled from self-report and medical records data

Quit Line services. Barriers to use exist, such as the need to locate and call a number and allocate sufficient time to discuss a cessation plan with the Quit Line staff. Additionally, some subjects expressed a desire for more immediate action from the intervention instead of having to wait until they were discharged to put the tobacco cessation strategies discussed during the counseling session into practice. This suggests that the use of seamless referrals, through the electronic medical record of patients, to cessation programs and materials, initiated while they are still in the hospital, may be an important method to facilitate subject engagement with and adherence to a smoking cessation plan. This also may indicate that the level of counseling intervention was not high enough and subjects may benefit from more counseling sessions or longer counseling sessions. Referral systems of this kind have been shown to be effective and have been successfully implemented in

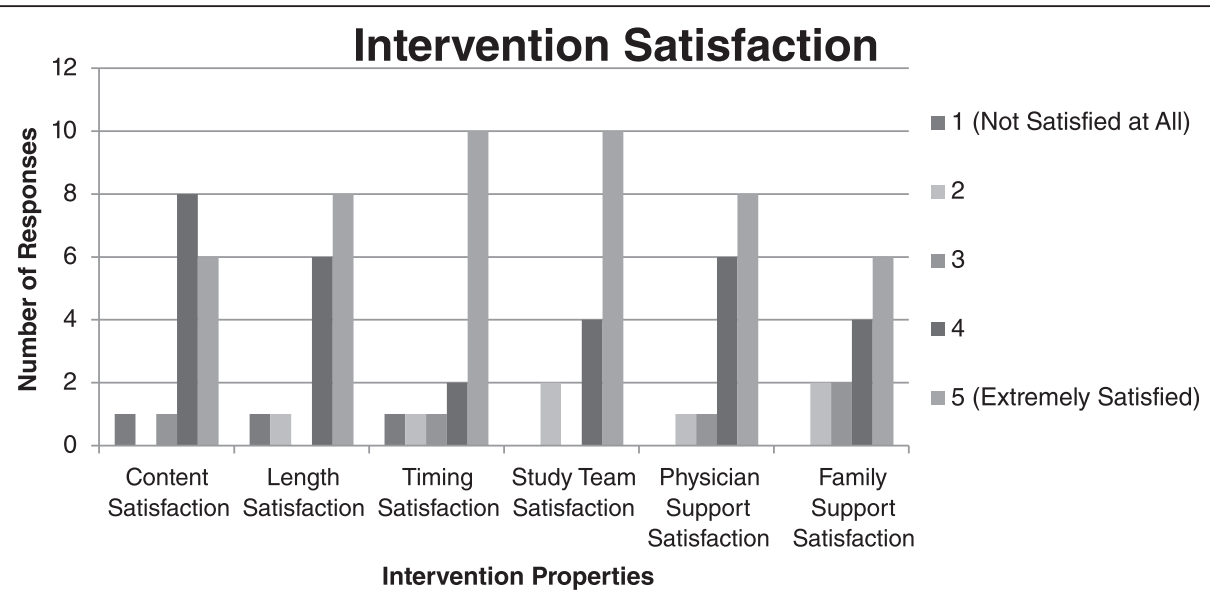

Fig. 2 Subject Satisfaction with Intervention Procedures. Legend: Number analyzed: Intervention group $n=16$ 
Table 3 Wisconsin Smoking Withdrawal Scale and Self-Efficacy Assessment (WSWS) mean scores at 1 week and 3 months

\begin{tabular}{|c|c|c|c|c|c|c|}
\hline \multirow[b]{2}{*}{ Scale } & \multicolumn{3}{|l|}{1 week } & \multicolumn{3}{|l|}{3 months } \\
\hline & $\begin{array}{l}\text { Intervention group } \\
\text { avg. score }\left(\mathrm{SD}^{\mathrm{a}}\right)(n=16)\end{array}$ & $\begin{array}{l}\text { Usual care avg. } \\
\text { score }\left(\mathrm{SD}^{\mathrm{a}}\right)(n=21)\end{array}$ & $p$-value ${ }^{*}$ & $\begin{array}{l}\text { Intervention group } \\
\text { avg. score }\left(S D^{\mathrm{a}}\right)(n=11)\end{array}$ & $\begin{array}{l}\text { Usual care avg. } \\
\text { score }\left(S D^{a}\right)(n=15)\end{array}$ & $p$-value \\
\hline Anxiety & $2.9(1.4)$ & $3.1(1.2)$ & 0.543 & $2.5(1.3)$ & $3.5(1.4)$ & 0.052 \\
\hline Impatience & $2.6(1.2)$ & $3.00(1.4)$ & 0.321 & $2.4(1.1)$ & $2.8(1.4)$ & 0.397 \\
\hline Bothered by Negative Moods & $2.8(1.3)$ & $2.9(1.4)$ & 0.734 & $2.5(1.2)$ & $2.9(1.2)$ & 0.518 \\
\hline Irritable or easily angered & $2.6(1.5)$ & $2.9(1.4)$ & 0.625 & $2.5(1.1)$ & $2.6(1.3)$ & 0.768 \\
\hline Depressed or Sad & $2.8(1.3)$ & $2.6(1.2)$ & 0.568 & $2.4(1.4)$ & $2.6(1.1)$ & 0.632 \\
\hline Hopeless or Discouraged & $2.5(1.2)$ & $2.2(1.0)$ & 0.407 & $2(1.1)$ & $2.5(1.1)$ & 0.285 \\
\hline Difficulty Paying Attention & $2.6(1.4)$ & $2.1(0.9)$ & 0.270 & $2.2(1.3)$ & $2.5(1.2)$ & 0.560 \\
\hline Difficulty Thinking Clearly & $2.4(1.2)$ & $2.2(1.0)$ & 0.497 & $2.0(1.1)$ & $2.5(1.1)$ & 0.239 \\
\hline Think of Food a lot & $2.5(1.5)$ & $3.2(1.2)$ & 0.137 & $2.1(1.0)$ & $3.1(1.1)$ & 0.020 \\
\hline Hunger & $2.8(1.1)$ & $3.4(1.2)$ & 0.090 & $2.5(1.1)$ & $3.3(1.2)$ & 0.075 \\
\hline Craving & $2.8(1.3)$ & $3.1(1.1)$ & 0.473 & $2.6(1.4)$ & $2.9(1.4)$ & 0.592 \\
\hline Self-Efficacy Assessment** & $2.1(0.9)$ & $2.7(1.2)$ & 0.088 & $2.4(1.2)$ & $2.2(0.9)$ & 0.642 \\
\hline
\end{tabular}

${ }^{\mathrm{a}} \mathrm{SD}=$ Standard deviation

*Data analyzed using $t$-tests

WSWS scores are measured on an agreement scale of $1-5 ; 1=$ "strongly disagree". $2=$ "disagree", $3=$ "neutral" $4=$ "agree", $5=$ "strongly agree"

${ }^{* *}$ One subject did not respond to the self-efficacy statement in the intervention group; $(N=10)$

hospital inpatient settings and should therefore be explored further as part of the cessation program [23]. Second, the timing of the intervention may also be important. Some subjects expressed that the counseling session may be more effective if performed closer to their discharge from the hospital so that they were less distracted by their hospital treatments and more likely to retain the information.

We found that participants in both groups had high rates of post discharge emergency room visits and hospital readmission, as well as high rates of new infection including pneumonia, surgical site infection, sinus infection, and urinary tract infection in the 3-month period of follow-up. Furthermore, approximately $21 \%$ of our sample was colonized by S.aureus at baseline and one subject observed as negative at baseline became positive at discharge. The higher rates of infection at admission however, may have played a role in the rates of infection seen at and post discharge. Ultimately, these high rates of infection and healthcare utilization highlight the susceptibility of this population to infections and may also be useful in determining the effect size and sample size needed in a larger study of tobacco cessation as a tool to reduce HAIs.

Our study extends current literature in this area. Rigotti et al. undertook a prospective observational study of six hundred fifty adult smokers admitted to the medical and surgical services of a large urban teaching hospital and found that only 34 of 650 smokers (5.2\%) received nicotine replacement therapy (NRT) during their hospital stay [24]. The authors also note that NRT was typically used to lessen nicotine withdrawal symptoms without taking into account the patient's ultimate tobacco cessation goals but did not offer suggestions as to why this may be. Ultimately, they concluded that the use of NRT should be increased in hospitalized smokers

Table 4 Positive and Negative Affect Schedule (PANAS) mean scores at 1 week and 3 months

\begin{tabular}{|c|c|c|c|c|c|c|}
\hline \multirow[b]{2}{*}{ Scale } & \multicolumn{3}{|l|}{1 week } & \multicolumn{3}{|l|}{3 months } \\
\hline & $\begin{array}{l}\text { Intervention group } \\
\text { avg. score }\left(S D^{\mathrm{a}}\right)(n=16)\end{array}$ & $\begin{array}{l}\text { Usual care avg. } \\
\text { score }\left(\mathrm{SD}^{\mathrm{a}}\right)(n=21)\end{array}$ & $p$-value & $\begin{array}{l}\text { Intervention group } \\
\text { avg. score }\left(S D^{a}\right)(n=11)\end{array}$ & $\begin{array}{l}\text { Usual care avg. } \\
\text { score }\left(\mathrm{SD}^{\mathrm{a}}\right)(n=15)\end{array}$ & $p$-value \\
\hline Distressed & $2.1(1.4)$ & $2.2(1.3)$ & 0.695 & $2.4(1.5)$ & $2.2(1.3)$ & 0.771 \\
\hline Upset & $2.1(1.3)$ & $2.3(1.3)$ & 0.718 & $2.4(1.6)$ & $2.5(1.4)$ & 0.862 \\
\hline Strong & $3.0(1.2)$ & $3.2(1.2)$ & 0.638 & $3.4(1.2)$ & $2.9(1.4)$ & 0.418 \\
\hline Enthusiastic & $2.6(1.3)$ & $2.9(1.2)$ & 0.489 & $2.9(1.2)$ & $3.0(1.3)$ & 0.859 \\
\hline Irritable & $2.4(1.6)$ & $2.5(1.5)$ & 0.869 & $2.5(1.5)$ & $2.4(1.4)$ & 0.925 \\
\hline Determined & $3.8(1.1)$ & $3.2(1.1)$ & 0.134 & $3.7(1.3)$ & $3.1(1.3)$ & 0.269 \\
\hline
\end{tabular}

${ }^{\mathrm{a}} \mathrm{SD}$ standard deviation

*Data analyzed using $t$-tests

PANAS scores are measured on an agreement scale of $1-5 ; 1=$ "strongly disagree". $2=$ "disagree", $3=$ "neutral" $4=$ "agree", $5=$ "strongly agree" 
to decrease nicotine withdrawal symptoms and also encourage tobacco cessation [24]. A recent published study protocol describes a multi-center, randomized clinical effectiveness trial planned to be conducted at Kaiser Permanente Northwest and at Oregon Health \& Science University (OHSU) hospitals in Portland, Oregon. It will recruit 900 hospital adult inpatients who smoke and will implement an intensive counseling intervention to examine cessation outcomes, with a primary outcome of self-reported 30-day smoking abstinence at 6 months post-randomization for intervention participants compared to usual care [25]. However, this study does not include assessment of healthcare-associated infection. Accordingly, our study sets the stage for a larger randomized trial to examine the impact of smoking cessation intervention on HAI and post discharge infections by first gathering critical data on the acceptability of such an intervention and feasibility in inpatient smokers as well as offering insight into the intervention methods that will be most successful.

Our study has several limitations. The sample size was small, restricting the ability to fully characterize potential tobacco cessation engagement and outcomes, as well as limiting the statistical power of our associations. Even with randomization, the usual care group showed much higher rates of infection at admission which may have influenced the rates of infections recorded at discharge and at each follow-up. There were also a high number of subjects lost to follow-up which could bias our observed results. Increasing sample size and limiting losses to follow-up may better randomize baseline infections between study groups and aid in distinguishing the possible effectiveness of the intervention and differences in outcomes. It was not possible in this study to use blinded reviewers for the follow-up assessments. Participation among those not interested in quitting was low, with many inpatients declining to participate. Many were simply not interested in quitting smoking at the time of recruitment or were too preoccupied with their current hospital stay to want to participate in a study. Accordingly, if the future intervention can more be seamlessly integrated into their hospital care, participation may increase. These limitations notwithstanding, our findings have implications for clinicians, infection preventionists and hospital personnel involved in efforts to prevent infections including HAI.

\section{Conclusions}

In conclusion, our results suggest that a brief face to face behavioral tobacco cessation intervention is feasible and acceptable for inpatient smokers. Study efficacy could be improved by the addition of a seamless referral mechanism to cessation programs and materials while the patient is still in the hospital and scheduling outpatient counseling at the end of a patient's stay. An important next step would be to evaluate the impact of this intervention on HAI and other infection rates in a large, adequately powered, randomized controlled trial.

\section{Ethics approval and consent to participate}

The study protocol was approved by the Institutional Review Board at the University of Wisconsin School of Medicine and Public Health.

\section{Abbreviations \\ HAl: hospital-acquired infection; MRSA: methicillin resistant Staphylococcus aureus; MSSA: methicillin susceptible Staphylococcus aureus; NRT: nicotine replacement therapy; PANAS: positive and negative affect schedule; SD: standard deviation; WSWS: wisconsin smoking withdrawal scale.}

\section{Competing interests}

The authors declare that they have no competing interests.

\section{Authors' contributions}

DS, SW, and NS drafted the manuscript. DS performed patient assessment and intervention. MD and SW performed the microbiology assays. NS and DKS participated in the design of the study and performed the statistical analysis. SV, DJ, SC, JS, and NS conceived of the study, and participated in its design and coordination and helped to draft the manuscript. All authors read and approved the final manuscript.

\section{Funding}

This research was supported by grant 9P50CA143188 from the National Cancer Institute to the University of Wisconsin Center for Tobacco Research and Intervention. This work was supported by a Health Services Research and Development Service Merit Review Award Pilot Project, Program Award \# 121HX001490-1 (Dr. Safdar). The views expressed in this article are those of the author(s) and do not represent the views of the U.S. Department of Veterans Affairs or the United States Government. This project was supported by grant number R18HS024039 from the Agency for Healthcare Research and Quality (Dr. Safdar). The content is solely the responsibility of the authors and does not necessarily represent the official views of the Agency for Healthcare Research.

\section{Author details}

${ }^{1}$ Department of Medicine, University of Wisconsin-Madison School of Medicine and Public Health, Madison, WI, USA. ${ }^{2}$ Department of Population Health Sciences, University of Wisconsin - Madison School of Medicine and Public Health, Madison, WI, USA. ${ }^{3}$ Center for Tobacco Research and Intervention, University of Wisconsin-Madison, Madison, WI, USA. ${ }^{4}$ Betty Irene Moore School of Nursing, University of California Davis, Sacramento, CA, USA. ${ }^{5}$ University of Wisconsin Hospitals and Clinics, Madison, WI, USA. ${ }^{6}$ William S. Middleton Memorial Veterans Affairs Medical Center, 5221 MFCB, 1685 Highland Avenue, Madison, WI 53705, USA.

Received: 6 January 2016 Accepted: 17 April 2016

Published online: 26 April 2016

\section{References}

1. Woloshin S, Schwartz LM, Welch HG. The risk of death by age, sex, and smoking status in the United States: putting health risks in context. J Natl Cancer Inst. 2008;100(12):845-53.

2. Zhang Z, Kofonow JM, Finkelman BS, et al. Clinical factors associated with bacterial biofilm formation in chronic rhinosinusitis. Otolaryngol Head Neck Surg. 2011;144:457-62.

3. Olsen K, Falch BM, Danielsen K, et al. Staphylococcus aureus nasal carriage is associated with serum 25-hydroxyvitamin D levels, gender and smoking status. The Tromso Staph and Skin Study. Eur J Clin Microbiol Infect Dis. 2012;31:465-73.

4. Faoagali JL. Carriage of N meningitidis. N Z Med J. 1995:108:415.

5. Durmaz R, Tekerekoglu MS, Kalcioglu T, Ozturan O. Nasal carriage of methicillin-resistant Staphylococcus aureus among smokers and cigarette factory workers. New Microbiol. 2001;24:143-7. 
6. Bagaitkar J, Demuth DR, Scott DA. Tobacco use increases susceptibility to bacterial infection. Tob Induc Dis. 2008;4:12.

7. Mehta H, Nazzal K, Sadikot RT. Cigarette smoking and innate immunity. Inflam Res. 2008;57:497-503.

8. Sopori M. Effects of cigarette smoke on the immune system. Nat Rev Immunol. 2002;2:372-7.

9. Rogers MA, Greene MT, Saint S, et al. Higher Rates of Clostridium difficile Infection among Smokers. PLoS ONE. 2012;7(7):e42091.

10. Christenson M, Hitt JA, Abbott G, Septimus EJ, Iversen N. Improving patient safety: resource availability and application for reducing the incidence of healthcare-associated infection. Infect Control Hosp Epidemiol. 2006;27:245-51.

11. Ferguson JK. Preventing healthcare-associated infection: risks, healthcare systems and behaviour. Intern Med J. 2009:39:574-81.

12. Marcel JP, Alfa M, Baquero F, et al. Healthcare-associated infections: think globally, act locally. Clin Microbiol Infect. 2008:14:895-907.

13. Stevens VJ, Glasgow RE, Hollis JF, Lichtenstein E, Vogt TM. A smokingcessation intervention for hospital patients. Med Care. 1993;31:65-72.

14. Miller NH, Smith PM, DeBusk RF, Sobel DS, Taylor CB. Smoking cessation in hospitalized patients. Results of a randomized trial. Arch Intern Med. 1997; 157:409-15.

15. Rigotti NA, Munafo MR, Stead LF. Smoking cessation interventions for hospitalized smokers: a systematic review. Arch Intern Med. 2008;168:1950-60.

16. Fiore M, Jaén CR, Baker TB, Bailey WC, Bennett G, Benowitz NL et al. A clinical practice guideline for treating tobacco use and dependence: 2008 update. A U.S. Public Health Service report. Am J Prev Med. 2008;35(2):158-76.

17. Thorndike AN, Rigotti NA, Stafford RS, Singer DE. National patterns in the treatment of smokers by physicians. JAMA. 1998;279:604-8.

18. Lewis SF, Piasecki TM, Fiore MC, Anderson JE, Baker TB. Transdermal nicotine replacement for hospitalized patients: a randomized clinical trial. Prev Med. 1998;27:296-303.

19. University of Wisconsin Center for Tobacco Research and Intervention. Wisconsin Tobacco Quit Line. 2014. http://www.ctri.wisc.edu/ql-smokers. htm. Accessed 12 Dec 2014

20. Identifying Healthcare-associated Infections (HAl) for NHSN Surveillance. Centers for Disease Control and Prevention. http://www.cdc.gov/nhsn/PDFs/ pscManual/2PSC_IdentifyingHAls_NHSNcurrent.pdf. Accessed 15 Dec 2014.

21. Watson D, Clark LA, Tellegen A. Development and validation of brief measures of positive and negative affect: the PANAS scales. J Pers Soc Psychol. 1988:54:1063-70.

22. Welsch SK, Smith SS, Wetter DW, Jorenby DE, Fiore MC, Baker TB. Development and validation of the Wisconsin Smoking Withdrawal Scale. Exp Clin Psychopharmacol. 1999;7:354-61.

23. Adsit RT, Fox BM, Tsiolis T, et al. Using the electronic health record to connect primary care patients to evidence-based telephonic tobacco quitline services: a closed-loop demonstration project. Transl Behav Med. 2014;1-9.

24. Rigotti NA, Arnsten JH, McKool KM, Wood-Reid KM, Singer DE, Pasternak RC The use of nicotine-replacement therapy by hospitalized smokers. Am J Prev Med. 1999:17:255-9.

25. Fellows JL, Mularski R, Waiwaiole L, Funkhouser K, Mitchell J, Arnold K. Health and economic effects from linking bedside and outpatient tobacco cessation services for hospitalized smokers in two large hospitals: study protocol for a randomized controlled trial. Trials. 2012;13:129.

\section{Submit your next manuscript to BioMed Central and we will help you at every step:}

- We accept pre-submission inquiries

- Our selector tool helps you to find the most relevant journal

- We provide round the clock customer support

- Convenient online submission

- Thorough peer review

- Inclusion in PubMed and all major indexing services

- Maximum visibility for your research

Submit your manuscript at www.biomedcentral.com/submit

) Biomed Central 